\title{
Para um uso não dualista dos conceitos vigotskianos, entre questionamentos psicológicos e sociológicos ${ }^{1}$
}

Jean-Yves Rochex*

Tradução: Isabela Silva Casquer ${ }^{2 * *}$

Revisão técnica: Débora Cristina Piotto ${ }^{* * *}$

O chamado à apresentação no colóquio ${ }^{3}$ de onde surge a presente obra convida o leitor a avaliar as contribuições e os limites do trabalho de Vigotski a "pensar a educação e a formação", principalmente face aos "ataques em larga escala dos quais a escola é hoje vítima". Tal desafio requer, sem dúvida, a renovação de nossas perguntas sobre a escola e a escolarização. Entretanto, o que será aqui discutido não pode ser feito somente sob o ponto de vista escolar ou didático, sem repensar a relação entre o que a escola é ou não é, sem analisar de perto o que se importa ou se exporta, o que circula, se confronta e atua a partir de um universo de socialização ou de uma esfera de experiência com o outro, as relações de continuidade, descontinuidade e ruptura, e as modalidades de troca ou desqualificação entre os diferentes modos de fazer e de pensar que estão em prática. Também sustentarei aqui uma reflexão e discussão já iniciadas em colóquios anteriores dedicados à fecundidade do trabalho de Vigotski (JOIGNEAUX;

\footnotetext{
${ }^{1}$ Texto publicado por Presses Universitaires de Bordeaux no livro "Vygotski et l'école: apports et limites d'un modèle théorique pour penser l'éducation et la formation" ("Vigotski e a escola: contribuições e limites de um modelo teórico para pensar a educação e a formação"), organizado por Jean-Paul Bernié e Michel Brossard, em 2013.

* Doutor em Ciências da Educação pela Universidade Paris VIII e professor na mesma universidade (coordenador do Laboratório ESCOL-CIRCEFT - Éducation, Socialisation et Collectivités locales/Centre Interuniversitaire de Recherche «Culture, Éducation, Formation, Travail »). Endereço eletrônico: jyrochex@gmail.com

** Licenciada em Pedagogia pela Faculdade de Filosofia, Ciências e Letras de Ribeirão Preto, da Universidade de São Paulo. Pesquisadora no Grupo de Estudos sobre Sucesso e Fracasso Escolar (GESFE), na Universidade de São Paulo. Endereço eletrônico: isabela.casquer@alumni.usp.br.

*** Doutora em Psicologia Escolar e do Desenvolvimento Humano pelo Instituto de Psicologia da Universidade de São Paulo (USP) e docente na Faculdade de Filosofia, Ciências e Letras de Ribeirão Preto / USP. Endereço eletrônico: dcpiotto@,usp.br

${ }^{2} \mathrm{O}$ autor refere-se ao $5^{\circ}$ Seminário Internacional Vygotski ("Vygotski et l'école"), ocorrido em 2011, na cidade francesa de Bordeaux e que deu origem ao livro em que o presente artigo foi originalmente publicado.
} 
ROCHEX, 2008; ROCHEX, 2012), que exige que os autores e seus quadros teóricos se encontrem e dialoguem, mas, que, também, se discuta as diferentes abordagens e as várias questões disciplinares, relativas, em particular, às disciplinas da psique e às disciplinas do social. Esta necessidade parece ainda mais inevitável se quisermos obter os meios para pensar não apenas as questões de desenvolvimento ou de relações entre o desenvolvimento e a aprendizagem em geral, mas também as desigualdades de aprendizagem e sucesso escolar, em desenvolvimento desigual ou impedido.

Será que o modelo teórico e os conceitos que Vigotski nos deixou podem nos ajudar a ir além do que, na pesquisa educacional, sempre aparece como uma parte do trabalho, teórico e empírico, entre, de um lado, uma sociologia da educação e das desigualdades educacionais relutantes em se interessar pelas funções e pelos métodos práticos de disseminação, transmissão e apropriação - formais ou informais - do estudo e do uso dos conhecimentos e das ferramentas/instrumentos culturais, tanto dentro quanto fora da escola, e, de outro, uma pesquisa em psicologia ou didática das disciplinas insuficientemente interessada nos aspectos sociais dos alunos e nas formas com as quais os diferentes contextos e processos de socialização dão forma e conteúdo às suas experiências e às suas disposições? Sim, certamente, mas, com a condição de que não façam dos textos ou conceitos de Vigotski figuras emblemáticas ou objetos de fetiche utilizados apenas como celebração ou exegese, ou como argumento de autoridade para justificar posições a priori, como muitos dos que se escondem atrás do nome do psicólogo soviético fazem, a fim de alimentar "as figuras impostas do debate pedagógico" opondo a preocupação com o aluno (ou com a criança) à com os saberes e com as disciplinas, muitas vezes, pensando no aluno e em seu desenvolvimento de um modo genérico, "solipsista" e "antissocial", enquanto outros, preocupados em defender as disciplinas, ou mesmo as didáticas disciplinares, às vezes, tem dificuldade em pensar que elas não relevam somente as limitações e as necessidades de ordem didática e epistemológica, mas também os processos sociais e institucionais, da herança elitista e dogmática de uma escola que é, também, uma escola de classe. Portanto, com a condição de colocar à prova a robustez e a vitalidade do trabalho de Vigotski para as questões e situações de hoje. Tentei mostrar, em um texto anterior (ROCHEX, 2012), o quanto isso me pareceu ter que passar por um exame crítico e por um uso menos extenso e mais específico dos conceitos vigotskianos de instrumentos, de mediação ou, novamente, do social, de maneira a dar (novamente) à teoria de Vigotski e à tese da gênese social do psiquismo, sua plena dimensão sociológica, para que assim ela possa desenvolver sua plena dimensão psicológica. O presente texto visa a continuar a reflexão iniciada anteriormente, retomando aos comentários e às práticas comuns que geralmente são feitas por certos pares conceituais (oralidade versus escrita, conceitos espontâneos versus científicos...) considerados como os mais importantes de seu modelo teórico. Este retorno parece ainda mais necessário devido aos temas das contribuições agrupadas nesta 
parte da presente obra ${ }^{4}$, uma vez que lidam com objetos, campos ou questões (early literacy ${ }^{5}$, desenvolvimento moral e construção de regras de conduta, circulação e uso de obras culturais e de recursos culturais de uma esfera de experiência para outra) que não se incluem em disciplinas escolares, nem se circunscrevem por um uso dualista dos termos específicos destes pares conceituais e nem atribuem a um dos espaços institucionais aos quais são mais frequentemente associados, ou mesmo identificados. Eles não pertencem apenas à esfera acadêmica, nem às esferas familiar ou juvenil, mas, transpassam tanto os limites das disciplinas quanto os das instituições.

Portanto, eles nos convidam a ir além do modo comum de pensar as relações entre as demandas e a cultura escolares e os modos de socialização familiar (ou juvenil) que são propícios aos diferentes aspectos sociais em termos de "distância cultural" ou de reconciliar, feliz ou infelizmente, consonante ou dissonante, entre universos, modos de relação com o mundo, com o conhecimento e com a linguagem, as práticas e as disposições, não apenas diferentes, mas que podem ser apreendidos de acordo com os dois pólos opostos que ecoam e, estruturalmente, homologam os termos da relação social de dominação. Por um lado, o capital e o babitus cultural disponíveis para as categorias dominantes e que estas transmitem de maneira formal e informal, intencional ou osmótica, aos seus filhos, permitiria que eles estivessem em uma relação de proximidade contínua com a cultura escolar, com o conhecimento e com a linguagem, além das disposições que esta requer e que constrói ao mesmo tempo, e, assim, ter acesso aos modos de fazer e pensar, bem como aos usos linguísticos e discursivos próprios da "razão" e do universo escolar (BERNSTEIN, 1975 e 2007; LAHIRE, 2008), da escrita e dos conceitos científicos, e dos comportamentos intencionais, conscientes, reflexivos e sistemáticos que permitem seu controle. Por outro lado, poderíamos explicar a persistência das desigualdades sociais no desempenho escolar das quais são vítimas as camadas populares e as classes dominadas, por conta de seu distanciamento, ou mesmo sua "não posse" do capital cultural legítimo e das disposições que lhe são associadas, da prevalência de seus modos de socialização familiar, que são essencialmente concebidos pelo sentido prático, e do "saberfazer" - imaterial ou material - que são ignorados como tais, esquecidos em sua eficácia, que não se separam dos atos e de sua implementação no contexto, e que não - ou dificilmente - permitiria aos estudantes e a seus pais reconhecer as regras do jogo (amplamente implícitas) da instituição e da "razão" escolar, ainda que se predispusessem a desenvolver atitudes e estratégias de resistência aos julgamentos de desqualificação social que são frequentemente expostos a seu respeito.

Vemos aqui como são progressivamente construídos, no raciocínio sociológico mais comum, dois pólos de noção colocados em correspondência aos habitus e aos modos de socialização cognitivolinguísticos considerados como próprios das diferentes camadas sociais (classes dominantes cultas versus populares dominadas), com a proximidade e com o distanciamento da instituição e da cultura escolares.

\footnotetext{
${ }^{4} \mathrm{O}$ autor refere-se à parte do livro em que o capítulo foi publicado originalmente.

${ }^{5}$ Letramento infantil (em inglês, no original).
} 
Este tipo de raciocínio, evidentemente, teve um forte poder heurístico, atestado por muitas obras importantes dos últimos anos. Porém, este poder heurístico parece ter se enfraquecido logo que procuramos complexificar a oposição binária entre classes dominantes e dominadas, ou entre sucesso e fracasso escolar, ao se concentrar nas práticas específicas observáveis nas famílias e nos espaços escolares. Tal visão parece-me levar a questionar as homologias, muito gerais, feitas em certos trabalhos com os pares conceituais emprestados ou atribuídos a diferentes autores (Vigotski, Goody, Bourdieu, Bernstein, Bakhtin...), lidos e utilizados de forma dualista e pouco dialética, com o risco de cair uns sobre os outros os diferentes regimes de determinação em que esses pares se inscrevem em uma espécie de teoria geral da Grande Divisa, de que conseguimos (mais ou menos racionalmente) criticar Goody em relação à oposição oral versus literacy ${ }^{6}$ e sociedades com escrita versus sem escrita (crítica que ele recusa: ver Goody, 2010), e que se repetiria ou se renomearia em diferentes oposições: erudita versus profano, conceitos científicos versus conceitos espontâneos, culturas desenvolvidas versus culturas populares, aprendizagens e formas escolares versus experiência comuns, ou, novamente, disposição escolar versus senso prático (em Bourdieu) e relação oral-pragmática versus escrita-escolar à linguagem e ao mundo, como em Lahire (1995). Podemos entender, nestas últimas formulações, não apenas a ambivalência - a que é muito difícil escapar, mesmo para aqueles que a levam à luz de Bourdieu - que se manifesta no duplo sentido denotativo e conotativo - dos termos escolástico ou escolar, mas também de certa tentação ou certo risco de fazer da escola uma instituição ou lugar onde, por excelência, se realiza a Grande Divisa, onde se misturam, até mesmo se confundem, os diversos regimes de determinação, de ordem epistemológica, social ou institucional.

Os usos demasiadamente globais e dualistas destes pares opostos conceituais, e os laços entre os diferentes regimes de determinação dos processos sociais de aprendizagem e do desenvolvimento, me parecem que devem ser questionados caso queiramos preservar o caráter heurístico das categorias e conceitos em que estes repousam. De um lado, porque são grandes os riscos de sugerir em pensar que os termos que se opõem - letramento versus oralidade, escola versus fora da escola, conceitos e regime de determinação de ordem científica e cotidiana, tipos secundários versus primários -, que são designados dos objetos ou dos processos intelectuais e linguísticos, das camadas sociais ou lugares institucionais, revelariam categorias em si mesmas, ou mesmo desenvolvimentos separados regidos pelas lógicas homogêneas ou pelo primado de uma lógica dominante, próprio(s), tanto em um lugar quanto em uma ordem de atividade. Assim, a escola seria, quase que por natureza, o local da razão gráfica ou da escrita, do desenvolvimento dos conceitos científicos, dos (tipos) e discursos secundários, enquanto que seu inverso ideal-típico, um fora da escola seria onde dominaria os sentidos práticos, o fazer nas situações e a relação primária com a linguagem e com o mundo, podendo ser encarnada, mesmo que de forma não perfeita, nas práticas e nos modos de socialização e de experiência comum das classes populares com

\footnotetext{
${ }^{6}$ Letramento (em inglês, no original).
} 
pouca ou nenhuma escolaridade. Este tipo de representação, apresentada aqui de forma esquemática, talvez quase caricata, pode, de qualquer forma, ser lida também de forma oposta, mesmo nos movimentos de balanço que, por um lado, combinam uma visão legitimista da escola e da cultura escolar e uma visão deficitária ou miserável das camadas e culturas populares ou juvenis, e, de outro, conjuga, pelo contrário, uma visão crítica da cultura escolar como relevante ou em maior parte arbitrária, e uma visão populista ou estética dos meios e das práticas populares (ver Grignon \& Passeron, 1989 ou, mais especificamente, pesquisa em educação, Daunay et al., 2009).

Escapar destas figuras opostas - mais ou menos rudimentares - e das homologias dualistas em que repousam, não é, evidentemente, algo fácil a fazer. Mas, a meu ver, isso não pode ser feito sem levar em consideração que não há, e provavelmente há cada vez menos e menos, correspondência estrita entre as formas e os modelos de aprendizagem ou de discursos e os lugares institucionais. Assim, muitas das características do que podemos chamar de a "forma escolar" (VINCENT, 1980, 1994) ou a "relação da escrita-escolar" à linguagem e ao mundo (LAHIRE, 1995) são amplamente difusas também fora da escola e relacionadas hoje em dia - e cada vez mais, embora de forma desigual de acordo com as origens sociais e as afiliações de gênero - a práticas sociais e "etnodidáticas" (MARKIDIS, 2007) implementadas no universo familiar ou nas diferentes esferas de experiência das crianças ou adolescentes que são os alunos. Mas, em troca, esta difusão fora de seu recinto pode levar a instituição escolar à lógica de "abertura", à “descompartimentação", e à implementação, consciente, deliberada ou impensada, de novos modos de "classificação" do conhecimento e novas formas de organizar os "discursos pedagógicos", muitas vezes justificados e argumentados - quando são -, em nome da "inovação", da "adaptação" à modernidade, ou mesmo da "democratização", cujos certos trabalhos possam conduzir a pensar que, longe de reduzilos, estes podem endossar, ainda que reforçando a opacidade que pesa sobre os requisitos de aprendizagem e de sucesso escolar para os alunos mais pobres e, assim, participar mais de certo "populismo pedagógico" do que de um compromisso de democratizar o acesso ao conhecimento (ver Bernstein, 2007; Rochex \& Crinon, 2011). Ir além das homologias dualistas também não será possível se não nos esforçarmos para inventariar melhor, pensar e estudar os objetos e os regimes de determinação “intermediários" ou "híbridos" que não são facilmente reduzidos ou classificados em um dos pólos, em uma das categorias de oposições ou de pares conceituais constitutivos destas homologias, e que nos convidam - e nos ajudam - a dialetizá-los, historicizá-los e, desse modo, designá-los.

Não podemos formular aqui a hipótese de que a dificuldade da pesquisa em educação (e isso inclui nosso próprio trabalho) em melhorar a consideração acerca destes processos de disseminação e migração entre universos escolares e "não escolares" de objetos intermediários ou híbridos entre a oralidade e o letramento, ou entre conceitos científicos e conceitos cotidianos, seria ainda mais forte porque estaria vinculada a uma dupla tentação escolástica ou didática. Por um lado, ela seria reforçada por uma postura de reduzir o que Goody ou Lahire nomearam de "razão gráfica" ou "razão escolar" a seu componente ou seu fundamento linguístico, vendo as práticas de leitura-escrita em seu sentido 
restrito. Porém, a linguística por si só não esgota a semiótica, e a insistência na escrita em seu sentido estrito corre o risco de diminuir a importância desses fundamentos da razão gráfica que Eduardo Marti chama de "sistemas de representação externos e permanentes, organizados espacialmente e graficamente", entre os quais, claro, inclui a própria escrita, mas, também "os desenhos, as notações numéricas, os mapas, as tabelas ou os gráficos", ferramentas ou técnicas de externalização e objetivação da memória e do intelecto, que ele acredita que não deve ser considerado como um bloco para assim poder pensar melhor e estudar, ao mesmo tempo, as diferenças e as relações de interdependência (MARTI, 2008). São esses componentes pré ou extra-linguísticos de razão gráfica (ou de literacy) que estão no centro de toda uma veia de trabalho sobre early literacy, sobre os quais Christophe Joigneaux nos convida a pensar na gênese e na co-construção entre as práticas familiares (ver as obras fundadoras de Heath, 1982 e 1983) e as práticas de escolarização, particularmente na pré-escola (JOIGNEAUX, 2009 e neste volume $e^{7}$; ou sobre os quais Jacques Bernardin focaliza a sua atenção mostrando como "a cultura escrita não se resume à escrita", mas, participa, por exemplo, por meio do uso do desenho ou esquema - sistemas externos de representação -, da elaboração de uma nova relação com objetos técnicos e uma técnica verdadeiramente cultural (BERNARDIN, 1997). Esses componentes não linguísticos da razão gráfica ou escolar, que são os sistemas permanentes de representação, além da escrita no sentido estrito, e compartilham com ele algumas das características que Vigotski insiste sobre a comunicação escrita: o uso voluntário, consciente e sistemático. Neste sentido, suas utilizações participam, desde a primeira socialização ou pré-escolarização - ou mesmo antes que as crianças sejam confrontadas com o ensino da leitura-escrita e das disciplinas escolares e, mais tarde, paralelamente a esse confronto -, da construção de dispositivos para o trabalho de estudo, da Skholé, no sentido de ajustar um tempo e um espaço específicos, permitindo tomar uma pequena distância em relação ao curso da experiência, e, então, fazer um retorno a esta. Há, ao que me parece, uma dimensão pré-disciplinar - ou pelo menos infra-didática , na qual Pierre Oléron já insistiu quando enfatizou que a eficiência do raciocínio "só é possível se o sujeito não reagir imediatamente à situação ou ao problema colocado, mas efetuar o desvio para a reflexão, dúvida, mobilização ou elaboração de um plano, de um esquema, de uma representação da situação, de sua ação e suas consequências" (OLÉRON, 1989). Seria essencial, assim, para partir da segunda tentação escolástica ou didática que acabei de mencionar, se pensar nesta dimensão própria do trabalho de estudo e de seu desenvolvimento, sem identificá-los como disciplinas e didáticas disciplinares, nem mesmo a suas premissas, a fim de estudar a contribuição para ambos os fundamentos de aprendizagem disciplinar e para desenvolver as relações de interdependência e de intersignificação (BAUBION-BROYE, 1998) que se estabelecem no desenvolvimento dos sujeitos. Isso se refere à necessidade de melhor trabalhar as montantes, as jusantes, mas também os entornos das aprendizagens escolares fora da escola e, portanto, especificando, de acordo com as camadas sociais, as configurações

\footnotetext{
${ }^{7} \mathrm{O}$ autor refere-se ao livro em que o texto foi originalmente publicado.
} 
familiares e as afiliações de gênero, que são os modos de mediação e o uso dos instrumentos e técnicas do intelecto e da ação nas diferentes esferas da experiência das crianças ou adolescentes, que compõem o alunado. Por exemplo, quanto à gênese do early literacy em famílias cuja análise é essencial para "estudar como a mediação dos pais pode ser eficaz na melhoria do desempenho escolar" (KOZULIN, 2009), mas também para mostrar o quanto a instituição escolar tende a pressupor que todas as crianças que ela acolhe são ou deveriam ser amplamente dotadas de modos de relação com a escrita e das disposições do trabalho de estudo, que constituem as práticas de early literacy implementadas dentro das classes médias cultas. Além disso, igualmente, se questionarmos como os alunos podem fazer uso de recursos - saberes e obras - que eles se apropriam mais na escola do que em outras esferas de sua existência, que eles podem “cultivar" lhes conferindo um sentido pessoal irredutível ao seu significado social (LEONTIEV, 1984) e suscetíveis de permitir criar novas relações entre essas esferas de experiência (ver Zittoun \& Grossen, 2012; Zittoun, neste volume). Finalmente, se levarmos a sério o fato de que a escola também é um lugar de desenvolvimento moral e de aprendizagem das regras da vida coletiva e da cooperação, que podem ser mediadas pelas "instituições", como a classe cooperativa e o conselho de classe estudado por Maria Pagoni (2011 e neste volume), que define lugares e funções entre os quais os alunos podem e devem aprender a disseminar de forma relativamente independente seu desempenho ou status escolar e suas afinidades, aumentamos, assim, suas capacidades de generalização e contextualização.

Estes exemplos e as seguintes contribuições nos obrigam a relativizar, historicizar e dialetizar as diferenças e as oposições geralmente feitas entre o que a escola é e o que não é; entre o que pertence às disciplinas e suas didáticas e o que não se relaciona a isso. Do mesmo ponto de vista da "razão" escolar ou disciplinar, esta necessidade de se pensar mais dialética e atenciosamente às variações dos contextos históricos e sociais parece igualmente imperativa em relação, em particular, à diferenciação ou oposição feita por Vigotski e à retomada, de maneira recorrente, por muito de seus seguidores, entre conceitos e pensamentos científicos versus conceitos e pensamentos cotidianos. E assim talvez nós não possamos tirar todo o proveito que a obra de Vigotski nos oferece. Tentei, em um texto anterior (ROCHEX, 2012), demonstrar como o capítulo 6 de "Pensamento e Linguagem", notadamente a discussão que Vigotski faz de algumas publicações de Piaget, insiste sobre o fato de que os conceitos cotidianos e os conceitos científicos possuem tanto uns quanto os outros uma eficácia e um potencial de desenvolvimento dentro de sua ordem e seus contextos próprios. E também sobre a necessidade de pensar suas relações não como relações de exclusão, uns tomando o lugar dos outros diminuindo ou desqualificando sua utilização e eficácia, mas, como relações de elaboração, de mediação e de desenvolvimento recíprocos, e assim tanto na história das formações sociais quanto na do desenvolvimento dos sujeitos. De sua parte, Christophe Joigneaux nos mostra todo o interesse que existe, do ponto de vista do que aqui está sendo discutido, em cruzar a leitura com o Capítulo 5, bem menos comentado, mas que esboça um levantamento de uma primeira aproximação de objetos ou processos intermediários ou híbridos entre os dois termos ou os dois polos de pares de conceitos científicos e conceitos cotidianos; objetos e processos cujo estudo parece 
ser uma maneira promissora de pensar sobre esses dois tipos de conceitos, menos no registro de sua oposição termo a termo, e mais nas cadeias de mediação que permitem a passagem progressiva de um para o outro e o seu possível desenvolvimento mútuo. Devemos nos deter, para desenvolver esta hipótese, no exemplo mais conhecido do objeto (e processos do pensamento e de categorização) intermediário ou híbrido que nos deu Vigotski, o psendo-conceito. Este é o "equivalente funcional" do conceito nas trocas linguísticas (que ele torna possível) entre criança e adulto, mas que se submete a processos de pensamento e categorização muito diferentes em um e em outro, que podem assim utilizar as mesmas palavras e concordar com sua referência durante essas trocas, porém, sem lhes conferir o mesmo significado. No capítulo 5 de "Pensamento e Linguagem”, escreve Vigotski: "É isso o que torna imensa a importância funcional do pseudo-conceito como uma forma particular, ambivalente e intrinsecamente contraditória do pensamento infantil. (...) Esta coincidência na referência concreta e esta 'não-coincidência' na significação da palavra, que nos apareceu como a particularidade essencial do pensamento infantil por complexos, não são a exceção, mas, sim a regra no desenvolvimento da linguagem". Portanto, são essas relações de discordância entre referente partilhado (e ação ou atenção) e significação da palavra (ou da situação), para a criança, que permitem à significação se desenvolver. Encontramos uma análise análoga sobre o jogo (VIGOTSKI, 1933/1978) quando Vigotski enfatiza a pluralidade dos níveis que o jogo imaginário comporta, e insiste sobre o fato de que a discrepância entre a situação concreta (jogar com um bastão) e a significação que lhe é atribuído (este bastão é um cavalo) pode fazer com que o jogo constitua uma Zona do Desenvolvimento Próximo para a criança - que, neste caso, não requer a intervenção direta dos outros -, o que lhe permite emancipar-se da situação imediata, de seus constrangimentos e situar-se "de alguma forma um nível acima de si mesma". Isso leva Vigotski a dizer que "a relação entre o jogo e o desenvolvimento pode ser comparada à relação entre instrução e desenvolvimento". Outros exemplos de tais discordâncias podem ser encontrados em diferentes textos de Vigotski. No entanto, eles não nos dizem muito mais sobre os processos de resolução da discordância que permitem o desenvolvimento. E é apropriado, nesta questão, se abster de qualquer "determinismo cognitivo ou desenvolvimental". Tais discordâncias apenas podem ser consideradas como fontes de desenvolvimento quando relacionadas a condições sociais, familiares ou escolares que permitem ultrapassá-las. Mas, elas podem igualmente ser, em outras condições menos felizes, fontes de malentendidos duráveis e, portanto, de desenvolvimento impedido para um indivíduo e de desenvolvimento desigual entre indivíduos. Isso levanta questões e exige investigações detalhadas, tanto pela psicologia quanto pela sociologia. Devo acrescentar que tais perspectivas de pesquisa não se preocupam somente com o desenvolvimento da criança, mas também, provavelmente, embora de maneira diferente, com o do adulto, no trabalho ${ }^{8}$ ou na vida social. Estas perspectivas, sem dúvida, exigiram uma investigação e uma análise sistemática - tanto para o adulto quanto para a criança - dos diferentes tipos de objetos e

\footnotetext{
${ }^{8}$ Cf, por exemplo, com o que escreveu Yves Clot a propósito de catacreses (CLOT, 1999).
} 
atividades intermediárias ou híbridas entre as características que são mais frequentemente atribuídas aos polos distintos dos pares conceituais que Vigotski pôde utilizar, tanto para se prevenir dos usos muito dualistas destes conceitos, quanto para melhor pensar como o registro do "espontâneo" ou do “cotidiano" não recua ou desaparece em face do desenvolvimento do registro "científico", mas, persiste e se desenvolve, e como o desenvolvimento de cada um desses dois registros se alimenta do desenvolvimento de suas relações. Essas perspectivas demandariam, igualmente, sob um registro mais teórico, se complexificar ou se questionar os pensamentos e as análises em termos de distânciaproximidade ou consonância-dissonância (que, muitas vezes, tratam a dissonância, a descontinuidade ou a conflitualidade como prejudiciais) para se interrogar sobre as condições - sociais, institucionais e psíquicas - de elaboração (e não de redução) da discordância e da conflitualidade e restaurar o conflito como o motor da historicidade, tanto para os sujeitos quanto para as formações sociais.

\section{REFERÊNCIAS}

BAUBION-BROYE, A. Événements de vie, transitions et construction de la personne. Toulouse: Érès, 1998.

BERNARDIN, J. Comment les enfants entrent dans la culture technique. Paris: Retz, 1997.

BERNSTEIN, B. Pédagogie, contrôle symbolique et identité: théorie, recherche, critique. Laval: Presses Universitaires de Laval, 2007.

BERNSTEIN, B. Langage et classes sociales: codes socio-linguistiques et contrôle social. Paris: Éditions de Minuit, 1975.

CLOT, Y. Avec Vygotski. Paris: La Dispute, 1999.

DAUNAY, B.; DELCAMBRE, I.; REUTER, Y. Didactique du français: le socio-culturel en question. Lille: Presses Universitaires du Septentrion, 2009.

GOODY, J. Myth, Ritual and the Oral. Cambridge: Cambridge University Press, 2010.

GRIGNON, C.; PASSERON, J. C. Le savant et le populaire: misérabilisme et populisme en sociologie et 
en littérature. Paris: Gallimard - Le Seuil, 1989.

HEATH, S. B. Ways with words: language, life and work in communities and classrooms. Cambridge: Cambridge University Press, 1983.

HEATH, S. B. What no bedtime story means: narrative skills at home and school. In: Language in Society, Stanford, n.11, p.49-76, 1982.

JOIGNEAUX, C. Desprocessus de différenciation dès l'école maternelle: historicités plurielles et inégalité scolaire. Thèse de doutorat dirigée par J. Y. Rochex, Université de Paris 8, 2009.

JOIGNEAUX, C.; ROCHEX, J. Y. La construction de l'élève à l'école maternelle: regards croisés et apports de Vigotski, Berstein et Goody. In: Brossard, M.; Fijalkow, J. Vigotski et les recherches en éducation et didactiques. Bordeaux: Presses Universitaires de Bordeaux, p.73-87, 2008.

KOZULIN, A. Outils psychologiques et apprentissage par médiation. In: Kozulin, A. et al. Vigotski et l'éducation: apprentissages, développement et contextes culturels. Paris: Retz, 2009.

LAHIRE, B. La raison scolaire: école et pratiques d'écriture, entre savoir et pouvoir. Rennes: Presses Universitaires de Rennes, 2008.

LAHIRE, B. Culture écrite et inégalités scolaires: sociologie de l'échec scolaire à l'école primaire. Lyon: Presses Universitaires de Lyon, 1993.

LEONTIEV, A. N. Activité, conscience, personnalité. Moscou: Éditions du Progrès, 1984.

MARKIDIS, K. Les didactiques des Autres. Sur la connaissance et la reconnaissance du didactique populaire. In: Communication au Colloque Savoirs et didactiques. Université de Rouen, 2006, Penser l'éducation, $\mathrm{n}^{\circ}$ hors série, p.173-181, 2007.

MARTI, E. Appropriation précoce des systèmes externes de représentation: apprentissage et développement. In: Brossard, M.; Fijalkow, J. Vigotski et les recherches en éducation et en didactiques. Bordeaux: Presses Universitaires de Bordeaux, p. 59-71, 2008.

OLÉRON, P. Le raisonnement. Paris: Presses Universitaires de France, 1989.

PAGONI, M. Développement moral et situations éducatives: contributions à l'étude du champ conceptuel de la loi en milieu scolaire. Habilitation à Diriger des Recherches, Université Paris 8, octobre 2011.

ROCHEX, J. Y. Des usages de Vigotski dans les débats et la recherche en éducation. In: Clot, Y. Vygotsky maintenant. Paris: La Dispute, p.41-60, 2012.

ROCHEX, J. Y.; CRINON, J. La construction des inégalités scolaires: au coeur des pratiques et dispositifs d'enseignement. Rennes: Presses Universitaires de Rennes, 2011.

VIGOTSKI, L. S. Play and its role in the mental development of the child. 1933. Disponível em: <http://www.cddc.vt.edu/marxists/archive/Vygotski/works/1933/play.htm>. Acesso em: 22 jul. de 2010.

VIGOTSKI, L. S. Mind in Society: the development of Higher Psychological Processes. 1935. Edit by M. Cole; V. John-Steiner; S. Scribner; E. Soubermann. Londres - Cambridge: Harvard University Press, 1978. 
VINCENT, G. L'école primaire française: étude sociologique. Lyon: Presses Universitaires de Lyon, 1980.

VINCENT, G.; LAHIRE, B.; THIN, D. L'école prisonnière de la forme scolaire? Lyon: Presses Universitaires de Lyon, 1994.

ZITTOUN, T.; GROSSEN, M. Cultural elements as means of constructing the continuity of the self across various spheres of experience. In: César, M.; Ligorio, B. The interplays between dialogical learnings and dialogical self. Charlotte, NC: InfoAge, p.99-126, 2012. 